\title{
Kappa opioid receptors in the central amygdala modulate spinal nociceptive processing through an action on amygdala CRF neurons
}

\author{
Guangchen $\mathrm{Ji}^{1,2}$ and Volker Neugebauer ${ }^{1,2,3^{*}}$
}

\begin{abstract}
The amygdala plays an important role in the emotional-affective aspects of behaviors and pain, but can also modulate sensory aspect of pain ("nociception"), likely through coupling to descending modulatory systems. Here we explored the functional coupling of the amygdala to spinal nociception. We found that pharmacological activation of neurons in the central nucleus of the amygdala (CeA) increased the activity of spinal dorsal horn neurons; and this effect was blocked by optogenetic silencing of corticotropin releasing factor (CRF) positive CeA neurons. A kappa opioid receptor (KOR) agonist $(\mathrm{U}-69,593)$ was administered into the CeA by microdialysis. KOR was targeted because of their role in averse-affective behaviors through actions in limbic brain regions. Extracellular single-unit recordings were made of CeA neurons or spinal dorsal horn neurons in anesthetized transgenic Crh-Cre rats. Neurons responded more strongly to noxious than innocuous stimuli. U-69,593 increased the responses of CeA and spinal neurons to innocuous and noxious mechanical stimulation of peripheral tissues. The facilitatory effect of the agonist was blocked by optical silencing of CRF-CeA neurons though light activation of halorhodopsin expressed in these neurons by viral-vector. The CRF system in the amygdala has been implicated in aversiveness and pain modulation. The results suggest that the amygdala can modulate spinal nociceptive processing in a positive direction through CRF-CeA neurons and that KOR activation in the amygdala (CeA) has pro-nociceptive effects.
\end{abstract}

Keywords: Amygdala, Kappa opioid receptor, Spinal dorsal horn, Nociception, Optogenetics

\section{Introduction}

The amygdala has emerged as an important node of the emotional-affective aspects of pain and pain modulation [1-6]. The central nucleus (CeA) serves major amygdala output functions and receives pain-related information through the spino-parabrachio-amygdala pathway as well

\footnotetext{
* Correspondence: volker.neugebauer@ttuhsc.edu

${ }^{1}$ Department of Pharmacology and Neuroscience, Texas Tech University

Health Sciences Center, School of Medicine, 3601 4th St, Lubbock, TX 79430-6592, USA

${ }^{2}$ Center of Excellence for Translational Neuroscience and Therapeutics, Texas Tech University Health Sciences Center, Lubbock, TX, USA

Full list of author information is available at the end of the article
}

as from thalamic and cortical regions through the basolateral amygdala network [2]. Importantly, synaptic plasticity in the CeA in different pain models has been linked to emotional responses such as vocalizations, aversive behaviors in conditioned place preference/aversion assays, and anxio-depressive behaviors [7-16]. The contribution of the amygdala to sensory aspects of pain such as hypersensitivity in pain models is less clear. Manipulations of amygdala activity provided evidence for dual pro- and anti-nociceptive effects [4, 17-26] but others had little, if any effect on hypersensitivity $[15,16$, 27-32]. The current view is that distinct amygdala 
circuits and cell types serve different functions related to different aspects of pain.

Nociceptive plasticity in the spinal dorsal horn plays a critical role in pain-related hypersensitivity [33, 34]. However, there is little information about the modulation of dorsal horn activity by the amygdala, although amygdala neurons project to and can modulate descending pain control centers such as periaqueductal gray PAG $[2,35$, 36]. A recent study showed that morphine injection into the CeA, but not anterior cingulate cortex (ACC), reduced the responses to spinal dorsal horn neurons to noxious mechanical stimulation in a neuropathic pain model [37]. And block of kappa opioid receptors (KOR) in the CeA restored the loss of diffuse noxious inhibitory control (DNIC) in a neuropathic pain model, implicating amygdala KOR in descending pain modulation.

Here we used a selective KOR agonist (U-69,593) to manipulate CeA neuronal activity and measure the consequences on spinal dorsal horn neurons. Interactions between the KOR and CRF systems have been linked to aversiveness, anxiety and stress responses [38], and amygdala CRF-CeA neurons project to brain areas involved in pain modulation such as PAG [39]. Therefore, we tested the contribution of CRF-CeA neurons to the spinal effects of KOR activation in the amygdala, using optogenetic silencing of CRF-CeA neurons.

\section{Materials and methods}

\section{Animals}

Male, hemizygous transgenic and wildtype Crh-Cre rats on Wistar background [39-41] (initial breeding pairs kindly provided by Dr. Robert Messing, UT Austin), $250-350 \mathrm{~g}$ at time of testing, were housed on a 12-h light-dark cycle with unrestricted access to food and water. On the day of the experiment, animals were acclimated to the laboratory for at least $1 \mathrm{~h}$. All procedures were approved by the Institutional Animal Care and Use Committee (IACUC) at the Texas Tech University Health Sciences Center (TTUHSC) and conformed to the policies and recommendations of the National Institutes of Health (NIH) Guide for the Care and Use of Laboratory Animals.

\section{Experimental protocol}

Single-unit recordings of CeA neurons were made in anesthetized naïve rats before, during and after administration of a KOR agonist $(\mathrm{U}-69,593)$ into the CeA by microdialysis $(15 \mathrm{~min})$. In some experiments, an AAV vector expressing halorhodopsin was injected into the CeA 4-5 weeks before the electrophysiology recordings to determine the effect of optical silencing of CRF-CeA neurons on the activity of CRF-CeA neurons. In these experiments, a recording electrode and a microdialysis or optical fiber were inserted into the CeA region. In another set of experiments, single-unit recordings of spinal dorsal horn neurons were made in anesthetized naïve rats before and during administration of U-69,593 into the CeA by microdialysis $(15 \mathrm{~min})$ and during optical silencing of CRF-CeA neurons while U-69,593 administration continued for another $15 \mathrm{~min}$. For the optogenetic experiments, an AAV vector expressing halorhodopsin was injected into the CeA $4-5$ weeks before. In these experiments, a microdialysis fiber and an optical fiber were inserted into the CeA.

\section{Systems electrophysiology Amygdala}

Extracellular single-unit recordings were made from neurons in the lateral-capsular division of the $\mathrm{CeA}$ in the right hemisphere as described previously [14, 32, 42, 43]. Rats were anesthetized with isoflurane (3-4\% induction, 2\% maintenance; precision vaporizer, Harvard Apparatus, Holliston, MA). Core body temperature was maintained at $37^{\circ} \mathrm{C}$ with a homeothermic blanket system. Using a stereotaxic frame (David Kopf Instruments, Tujunga, CA), a craniotomy was performed at the sutura frontoparietalis level for the insertion of the recording electrode (glass-insulated carbon filament electrode, 4-6 $\mathrm{M} \Omega$ ) and a microdialysis probe for drug or vehicle administration (see "Intra-amygdala drug application by microdialysis"), or an optical fiber for delivering yellow $(590 \mathrm{~nm})$ light pulses (see "Optogenetics"). A recording electrode was inserted stereotaxically into the CeA with a microdrive (David Kopf Instruments) using the following coordinates: $2.3-2.8 \mathrm{~mm}$ caudal to bregma, $3.8-4.2$ $\mathrm{mm}$ lateral to midline, 7-8 $\mathrm{mm}$ deep. The recorded signals (action potentials/spikes) were amplified, band-pass filtered ( $300 \mathrm{~Hz}$ to $3 \mathrm{kHz}$ ), and processed by an interface (1401 Plus; Cambridge Electronics Design, CED, Cambridge, UK). Spike2 software (version 4; CED) was used for spike sorting and data analysis. Spike size and configuration were monitored continuously. For each neuron, a spike template was created during a $5 \mathrm{~min}$ baseline recording period, capturing the waveform within set limits of variability for amplitude, duration, and rise time. Only those neurons were included in the study that showed a spike configuration that matched the preset template and could be clearly discriminated from activity in the background throughout the experiment. Neurons were identified by monitoring background activity and responses to search stimuli, i.e., compression of the contralateral hind paw at innocuous $\left(100 \mathrm{~g} / 6 \mathrm{~mm}^{2}\right)$ and noxious $\left(500 \mathrm{~g} / 6 \mathrm{~mm}^{2}\right)$ intensities with a calibrated forceps. Neurons were selected that had a receptive field in the hindpaw and were activated more strongly by noxious than innocuous mechanical stimuli. Neuronal activity was measured as spikes/s for $10 \mathrm{~min}$ (background activity in the absence of intentional stimulation) and 
then during mechanical test stimulation (compression of the paw for $15 \mathrm{~s}$ ). The interval between the innocuous stimulus and the noxious stimulus was $15 \mathrm{~s}$, and measurements were repeated about every $5 \mathrm{~min}$. For net evoked responses, background activity (spikes/15 s) preceding the stimulus was subtracted from the total number of spikes during stimulation (15 s).

\section{Spinal cord}

Extracellular single-unit recordings were made from wide dynamic range (WDR) neurons in the left spinal dorsal horn as described previously [44, 45]. WDR neurons respond more strongly to stimuli of noxious than innocuous intensities. Rats were anesthetized with isoflurane (3-4\% induction, $2 \%$ maintenance). Body temperature was maintained at $37^{\circ} \mathrm{C}$ with a homeothermic blanket system. A small laminectomy at vertebral levels T13-L2 exposed the lumbar spinal segments. Then the animal was mounted in a stereotaxic frame (David Kopf Instruments), the dura mater was opened, and a small pool was formed with agar to cover the exposed spinal cord with mineral oil. A glass insulated carbon filament electrode (4-6 M $\Omega$ ) was inserted perpendicularly to the spinal cord surface using a microdrive (David Kopf Instruments) to record the activity of WDR neurons in the deep dorsal horn $(300-1000 \mu \mathrm{m})$ of the lumbar enlargement of the spinal cord (L5/6). Signals (background activity and evoked responses) were recorded and analyzed as described for the amygdala.

\section{Intra-amygdala drug application by microdialysis}

A KOR agonist (U-69,593, Tocris Bioscience, R\&D Systems, Minneapolis, MN) was administered stereotaxically into the CeA by microdialysis while neurons in the CeA or spinal dorsal horn were recorded. At least $1 \mathrm{~h}$ before recordings started, a microdialysis probe (CMA/ Microdialysis 11, $240 \mu \mathrm{m}$ diameter, $6 \mathrm{kDa}$; Solna, Sweden) was inserted stereotaxically into the CeA (1.8$2.3 \mathrm{~mm}$ caudal to bregma, $4.0-4.5 \mathrm{~mm}$ lateral to midline, $8.0 \mathrm{~mm}$ deep) at a $5^{\circ}$ angle to allow simultaneous positioning of the recording electrode or optical fiber (see Optogenetics). The probe was connected to an infusion pump (Harvard Apparatus) with polyethylene tubing. Artificial cerebrospinal fluid (ACSF; in mM: $117 \mathrm{NaCl}$, $4.7 \mathrm{KCl}, 1.2 \mathrm{NaH} 2 \mathrm{PO} 4,2.5 \mathrm{CaCl} 2,1.2 \mathrm{MgCl} 2,25$ $\mathrm{NaHCO} 3$, and 11 glucose) was continuously perfused through the fiber at $5 \mu \mathrm{l} / \mathrm{min}$. ACSF served as control before and after administration of U-69,593. U-69,953 stock solution was diluted in ACSF to the final concentration $(100 \mu \mathrm{M})$, which is 100 -fold higher than the intended target concentration in the tissue due to the concentration gradient across the dialysis membrane and diffusion in the brain tissue [15, 45-48]. U-69,953 was administered into the CeA at a rate of $5 \mu \mathrm{l} / \mathrm{min}$ for at least $15 \mathrm{~min}$ to establish equilibrium in the tissue.

\section{Optogenetics}

For optical silencing of CRF-CeA neurons, a viral vector (rAAV5/EF1a-DIO-eNpHR3.0-eYFP, $1 \mu \mathrm{l}, 1012$ units/ $100 \mu \mathrm{l})$ packaged by the vector core facility at the University of North Carolina, Chapel Hill, NC was injected into the CeA using a $5 \mu$ Hamilton syringe (33 gauge) to express halorhodopsin in CRF neurons of the transgenic rats. Coordinates were as follows: $1.8-2.3 \mathrm{~mm}$ caudal to bregma, $4.0-4.5 \mathrm{~mm}$ lateral to midline, and $7.5 \mathrm{~mm}$ deep. 4-5 weeks were allowed for vector expression before the electrophysiology experiments. Light sensitive eNpHR3.0 (halorhodopsin) channels were activated with yellow $(590 \mathrm{~nm})$ laser light pulses $(20 \mathrm{~Hz}, 1-5 \mathrm{~mW}, 3-15 \mathrm{~min}$; Opto Engine LLC, Midvale, UT) through an optical fiber (200 $\mu \mathrm{m}$ diameter) inserted into the CeA. Pulsed optical activation of halorhodopsin in CRF-CeA neurons has been shown to silence these neurons [40].

\section{Histological verification of recording, drug administration and optical stimulation sites}

At the end of each experiment, the recording site in the CeA or spinal dorsal horn was marked with an electrolytic lesion by injecting DC $(250 \mu \mathrm{A}$ for $3 \mathrm{~min})$ through the recording electrode. The brain or spinal lumbar enlargement was removed and submerged in $10 \%$ formalin and potassium ferrocyanide. Tissues were stored in 30\% sucrose before they were frozen-sectioned at $50 \mu \mathrm{m}$ and stained with hematoxylin and eosin. Lesion/recording sites and locations of the tips of the microdialysis and optical fibers were identified under bright-field microscopy and plotted on standard diagrams (Fig. 1).

\section{Statistical analysis}

All averaged values are given as the mean \pm SE. Statistical significance was accepted at the level $P<0.05$. GraphPad Prism 7.0 software was used for all statistical analyses. Statistical analysis was performed on the raw data. Paired t-tests were used where appropriate. For multiple comparisons, ANOVA was used with Bonferroni posthoc tests.

\section{Results}

Experiments were designed to test the hypothesis that KOR activation in the amygdala under normal conditions increases activity of spinal dorsal horn neurons through the activation of CRF neurons in the amygdala (CeA).

\section{Facilitatory effects of KOR activation on $\mathrm{CeA}$ neurons}

Extracellular single-unit recordings of $19 \mathrm{CeA}$ neurons were made in 9 animals (1-2 neurons were studied in each animal). Recording sites in the lateral and capsular CeA are shown in Fig. 1d. Neurons were selected that responded more strongly to noxious than innocuous stimuli as in our previous studies $[14,49,50]$. In $8 \mathrm{CeA}$ 


\section{A. Microdialysis probes}

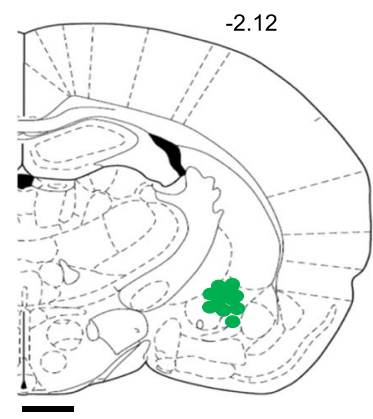

D. CeA recording sites
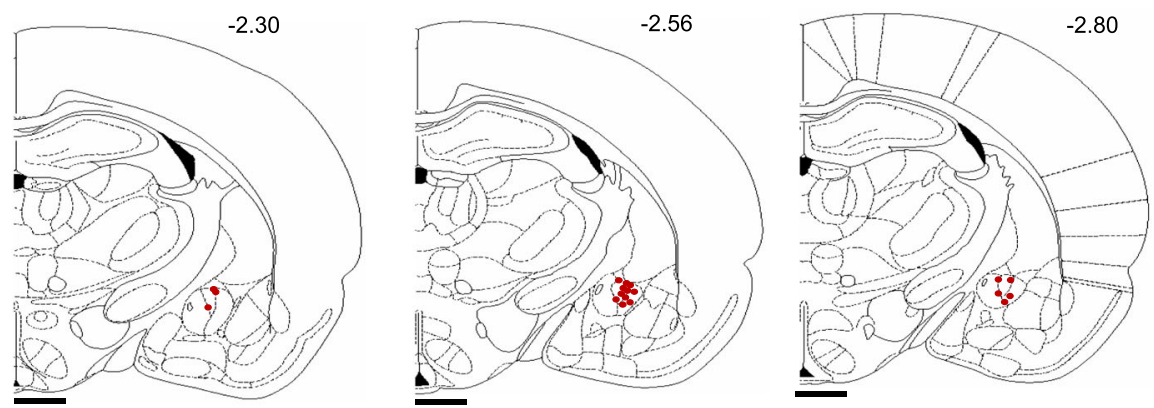

\section{E. Spinal dorsal horn recording sites}

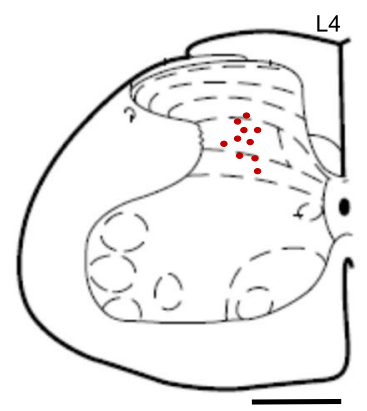

Fig. 1 Recording, drug administration and optical stimulation sites. a-d Coronal brain slices. Numbers next to diagrams indicate distance from bregma. a Location of tips of microdialysis probes in the CeA for drug application ( $n=12$ sites). $\mathbf{b}$ Location of tips of optical fibers for optogenetic stimulation of CRF-CeA neurons ( $n=8$ sites). c Confocal image of eYFP fluorescence in CRF neurons in the CeA following viral vector (rAAV5/EF1a-DIO-eNpHR3.0-eYFP) injection to express halorhodopsin (see Materials and Methods, Optogenetics). d Site of electrolytic lesions indicating recording sites in CeA. e Spinal cord slice showing recoding sites in the dorsal horn of lumbar segment L4. a-e Scale bars, $500 \mu \mathrm{m}$

neurons the effect of a KOR agonist (U-69,593, $100 \mu \mathrm{M}$ in microdialysis probe, $15 \mathrm{~min}$ ) administered into the CeA by microdialysis was tested (Fig. 2). U-69,593 increased background activity and evoked responses to innocuous and noxious mechanical stimuli (compression of the hindpaw with a calibrated forceps; for details see Materials Methods, "Systems Electrophysiology"). Facilitatory effects were significant $(P<0.05$ and $P<0.001$, compared to predrug ACSF, paired t-test, $n=8$; Fig. 2a, b, d, e). Drug application sites in the CeA are shown in Fig. 1a.

In another $11 \mathrm{CeA}$ neurons the effect of optical silencing of CRF neurons was tested 4-5 weeks after injection of viral vector (rAAV5/EF1a-DIOeNpHR3.0-eYFP) into CeA (see Fig. 1b; for details see Materials and Methods, "Optogenetics"). Optical silencing with yellow light pulses $(590 \mathrm{~nm}, 20 \mathrm{~Hz}, 1-$ $5 \mathrm{~mW}, 3-5 \mathrm{~min})$ significantly decreased the background activity of CeA neurons $(P<0.001$ compared to baseline, paired t-test, $n=11$; Fig. $2 \mathrm{c}$ and f). Labelled CRF neurons in the CeA following AAV injection are shown in Fig. 1c. The data suggest that KOR activation has facilitatory effects on CeA neurons whereas silencing of CRF neurons has inhibitory effects. 


\section{Amygdala neurons}

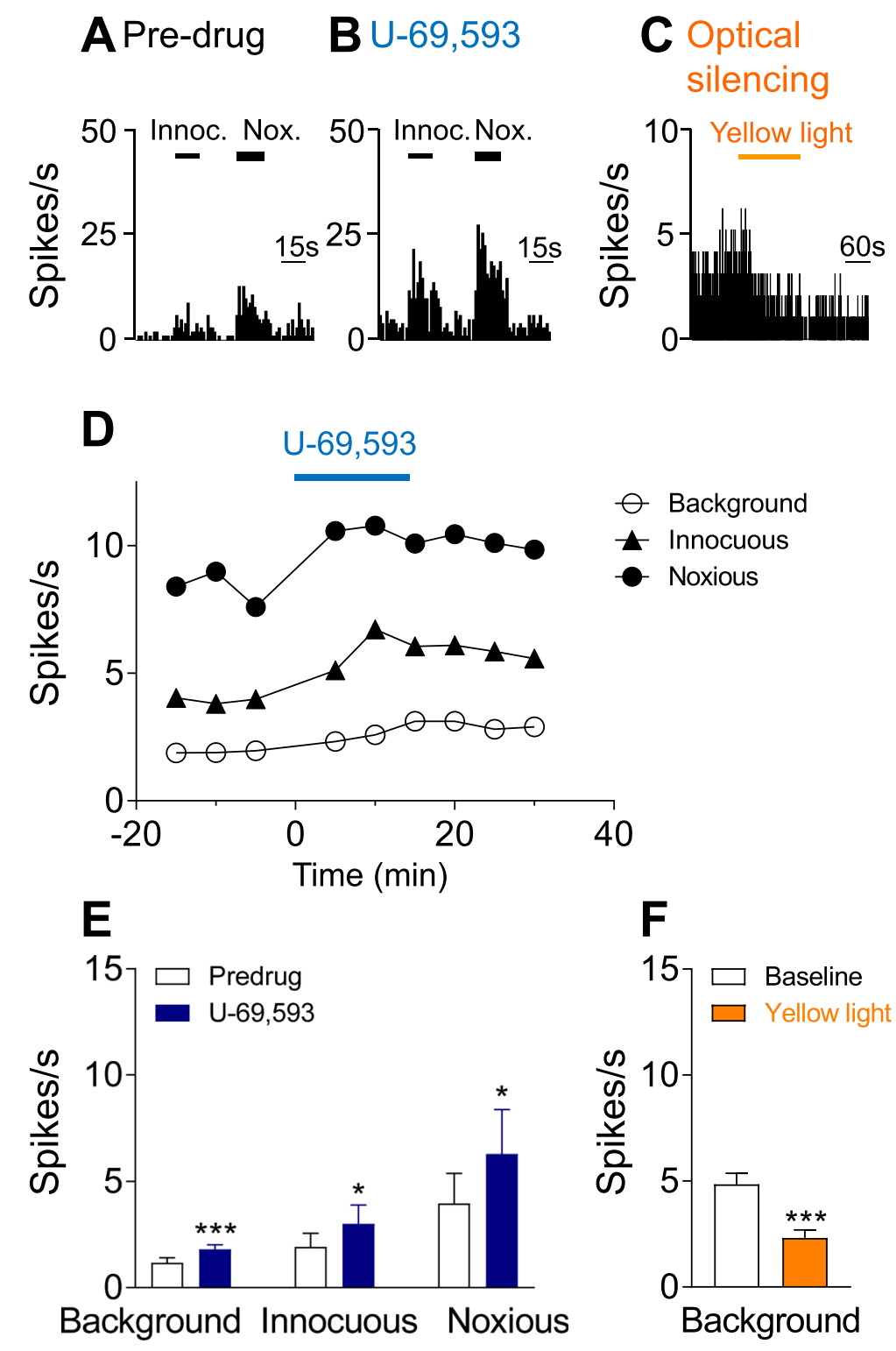

Fig. 2 Facilitatory effects of KOR activation and inhibitory effects of CRF-CeA silencing on CeA neurons. Extracellular single-unit recordings of 19 neurons in the lateral and capsular CeA in anesthetized rats. a-b Peristimulus time histograms show action potentials (spikes) per second in an individual CeA neuron before (pre-drug control in ACSF) and during administration of U-69,593 (100 $\mu \mathrm{M}$ in microdialysis probe, 15 min) into the CeA. Background activity and evoked responses (see Materials Methods) increased. c Peristimulus time histogram shows effects of optical silencing of halorhodopsin expressing CRF-CeA neurons by yellow light pulses (590 nm, $20 \mathrm{~Hz}, 1-5 \mathrm{~mW}, 3 \mathrm{~min}$ ) on action potential firing (see Materials and Methods, Optogenetics). $\mathbf{d}$ Time course of effects of U-69,593 in the same CeA neuron. e Summary of effects of U-69,593 in CeA neurons ( $n=8)$.* $P<$ 0.05 , ${ }^{* *} P<0.001$, compared to pre-drug ACSF, paired t-test. $\mathbf{f}$ Summary of effects of optical silencing of CRF-CeA neurons $(n=11) .{ }^{* *} P<0.001$, compared to baseline before optical stimulation, paired t-test. $\mathbf{e}, \mathbf{f}$ Bar histograms show mean $\pm S E$ for the sample of neurons

Facilitatory effects of KOR activation in CeA on spinal dorsal horn neurons were blocked by silencing CRF neurons in the $\mathrm{CeA}$

Using this information, we studied the effects of amygdala KOR activation on spinal dorsal horn neurons and examined the contribution of CRF neurons in the CeA.
Extracellular single-unit recordings of 10 spinal dorsal horn WDR neurons were made in 7 animals (Fig. 3). Recording sites in the deep dorsal horn of the left side of the lumbar cord are shown in Fig. 1e. WDR neurons responded more strongly to noxious than to innocuous stimuli applied to the hind paw (see Materials and 


\section{Spinal dorsal horn neurons}

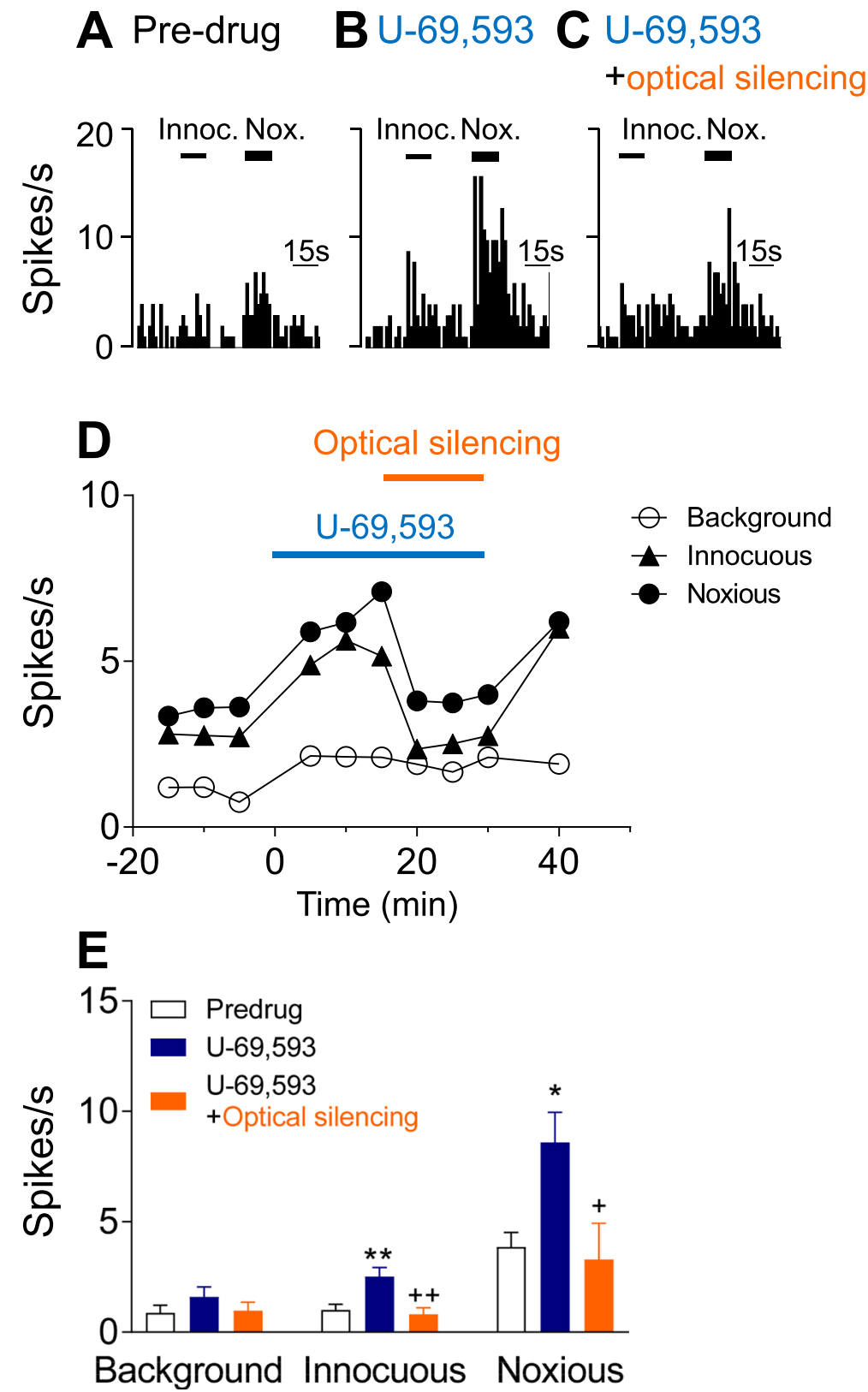

Fig. 3 Facilitatory effects of KOR activation in CeA on spinal dorsal horn neurons were blocked by silencing CRF neurons in the CeA. Extracellular single-unit recordings of 10 spinal dorsal horn WDR neurons in anesthetized rats. a-c Peristimulus time histograms show action potentials (spikes) per second in an individual spinal WDR neuron before (pre-drug control in ACSF; A) and during administration of U-69,593 (100 $\mu \mathrm{M}$ in microdialysis probe, $15 \mathrm{~min}$; B) into the CeA and during continued administration of U-69,593 while CRF-CeA neurons were silenced optogenetically $(590 \mathrm{~nm}, 20 \mathrm{~Hz}, 1-5$ mW, 3 min; C). Optical silencing of CRF-CeA neurons inhibited the facilitatory effects of U-69,593. d Time course of effects of U-69,593 in the CeA and optical silencing of CRF-CeA neurons on the same WDR neuron. e Summary of effects of U-69,593 in the CeA and optical silencing of CRF-CeA neurons on WDR neurons $(n=10)$. ${ }^{*} P<0.05,{ }^{* *} P<0.01$, compared to pre-drug ACSF; ${ }^{+} P<0.05,{ }^{++} P<0.01$, compared to U-69,593 alone; ANOVA with Bonferroni posthoc tests. See text for results of ANOVA. Bar histograms show mean \pm SE for the sample of neurons

Methods, "Systems Electrophysiology"). Administration of $\mathrm{U}-69,593(100 \mu \mathrm{M}$ in microdialysis probe, $15 \mathrm{~min})$ into the right $\mathrm{CeA}$ by microdialysis significantly increased responses to innocuous $\left(\mathrm{F}_{2,23}=7.43, P<0.01\right)$ and noxious stimuli $\left(\mathrm{F}_{2,23}=6.103, P<0.05\right.$, compared to pre-drug ACSF, ANOVA with Bonferroni posthoc tests, $n=10$; 
Fig. 3a, b, d, e). In 6 of these neurons, the effect of optical silencing ( $590 \mathrm{~nm}, 20 \mathrm{~Hz}, 1-5 \mathrm{~mW}, 15 \mathrm{~min}$ ) of CRF-CeA neurons was tested during continued administration of U$69,593(100 \mu \mathrm{M}$ in microdialysis probe) into the CeA for another $15 \mathrm{~min}$ (Fig. 3c, d, e). Optical silencing of CRFCeA neurons significantly inhibited the facilitatory effects of U-69,593 on responses to innocuous $\left(P<0.01, \mathrm{~F}_{2,23}=\right.$ $7.43)$ and noxious stimuli $\left(P<0.05, \mathrm{~F}_{2,23}=6.103\right.$; compared to U-69,593 alone; ANOVA with Bonferroni posthoc tests, $n=6$ ). Pulsed activation of halorhodopsin was used (see Methods, Optogenetics) that was shown before to silence CRF-CeA neurons [40]. Effects of optical silencing were reversible. Effects of U-69,593 and optical silencing on background activity did not reach the level of statistical significance $\left(\mathrm{F}_{2,23}=0.9726\right.$, ANOVA).

\section{Discussion}

The data presented here show that pharmacological activation of KOR in the CeA with U-69,593 increases activity of neurons in the CeA and in the spinal dorsal horn, suggesting a functional connection and positive correlation between neuronal activity in these regions. This connectivity was disrupted when CRF neurons in the CeA were silenced optogenetically, which suggests an important contribution of CRF neurons to amygdala output coupled to descending modulation of spinal nociceptive processing.

We focused on KOR to explore the amygdala-spinal cord connection because KOR in the amygdala have been linked to aversiveness, anxiety and stress responses $[38,51-54]$ as well as to averse-affective behaviors in stress- or injury-induced pain conditions [16, 55-57]. $\mathrm{KOR}$ is expressed in the CeA at particularly high levels [58]. We used a selective KOR agonist (U-69,593) [59] at a concentration that was based on data in the literature from electrophysiological studies in brain slices (see [60, 61]. U-69,593 has been shown to decrease synaptic inhibition of medial CeA neurons through a presynaptic action [60, 61]. U-69,593 also produced an outward current in medial CeA neurons, indicative of a postsynaptic inhibitory effect [62, 63]. Increased activity of lateral-capsular CeA neurons by U-69,593 in the present study is consistent with disinhibition observed in the brain slice studies [60,61]. The facilitatory effects of KOR activation in the CeA on spinal dorsal horn responses suggest a positive correlation and functional connection between amygdala activity and spinal nociceptive processing.

We studied KOR function in the right CeA because of evidence for right-hemispheric lateralization of CeA function $[49,64,65]$ and KOR function in the CeA related to pain modulation $[16,56,57,66]$. For example, blockade of KOR in the right, but not left, CeA restored diffuse noxious inhibitory control (DNIC), a measure of descending pain control $[56,57]$.

Evidence for functional links between amygdala KOR and CRF systems [38] let us to explore the contribution of CRF neurons to the descending modulation of nociceptive processing. CRF neurons in the CeA project to extra-amygdalar targets to promote averse-affective behaviors [39, 41, 67-69]. Amygdala CRF functions are under tonic inhibitory control of KOR as shown with a KOR antagonist that enhanced the synaptic effects of CRF on medial CeA neurons [70]. We used optogenetics to silence CRF neurons in transgenic Crh-Cre rats and found inhibitory effects on CeA neurons as well as inhibition of the facilitatory effects of U-69,593 on spinal neurons. The CeA cell type recorded in this in vivo study is not known but it is possible that they were CRF neurons that were inhibited directly with optical silencing. This scenario is supported by the fact that CRFCeA neurons project to brainstem areas involved in descending pain modulation such as the PAG [39]. Silencing of CRF neurons could also have effects on other types of CeA neurons that form long range projections including those containing somatostatin [71]. CRF neurons can excite [72] whereas somatostatin neurons inhibit [71] PAG neurons. In addition to coupling to brainstem centers involved in descending pain modulation, the amygdala CeA could influence spinal nociceptive processing through indirect influences on cortical regions such as ACC [73, 74] via cholinergic neurons in substantia innominata and nucleus basalis of Meynert [75]. CeA neurons do not directly project to cortical regions; main amygdala input to ACC arises from the basolateral amygdala [76]. Therefore, the amygdala can exert facilitatory influences on spinal nociceptive processing either through ascending or descending output to pain control systems $[73,77,78]$ by activating facilitatory or inhibiting inhibitory modulation. This remains to be determined.

On a technical note, prolonged application of U-69, 593 does not produce desensitization of CeA neurons [60]. This is important because our experimental protocol tested optical silencing of CRF-CeA neurons on the facilitatory effect of prolonged administration of U-69, 593 on spinal nociceptive processing. Therefore, reversal of the effects of U-69,593 by optical silencing of CRFCeA neurons was not due to desensitization. Finally, pulsed optical activation of halorhodopsin has been reported to evoke rebound spiking after hyperpolarization in certain cell types and brain regions [79, 80], which may not result in the desired silencing of neuronal activity. However, pulsed optical activation of halorhodopsin silenced CRF-CeA neurons without rebound spiking [40], which could be due to cell type, region and possibly species specific differences. 


\section{Conclusion}

This short communication provides important novel information about amygdalo-spinal interactions and the contribution of amygdala KOR and CRF systems. The data support the concept of a positive correlation and functional link between amygdala $(\mathrm{CeA})$ and spinal nociceptive processing. Details of the neural circuitry and cell-types remain to be determined.

\section{Abbreviations}

ACC: Anterior cingulate cortex; BLA: Basolateral nucleus of the amygdala; CeA: Central nucleus of the amygdala; CRF: Corticotropin releasing factor; KOR: Kappa opioid receptor; PAG: Periaqueductal grey

\section{Acknowledgments}

We thank Dr. Robert Messing, University of Texas at Austin, for kindly providing the initial Crh-Cre rat breeding pairs.

\section{Authors' contributions}

JG and VN conceived the study, designed the experiments and wrote the manuscript. JG carried out the experiments. Both authors participated in the data analysis and interpretation of results and read and approved the final manuscript.

\section{Funding}

Support for the authors' work was provided by National Institutes of Health (NIH) grants NS038261, NS106902 and NS109255.

\section{Availability of data and materials}

All data generated or analyzed during this study are included in this published article. Data files.

used for this manuscript are available via a direct and reasonable request to the corresponding.

author and approval from Texas Tech University Health Sciences Center (TTUHSC).

\section{Ethics approval and consent to participate}

All animal experiments were approved by the Institutional Animal Care and Use Committee (IACUC) at Texas Tech University Health Sciences Center, Lubbock, TX (\#14006, approved through 06/21/2021).

\section{Consent for publication}

Not applicable.

\section{Competing interests}

The authors declare that they have no competing interests.

\section{Author details}

${ }^{1}$ Department of Pharmacology and Neuroscience, Texas Tech University Health Sciences Center, School of Medicine, 3601 4th St, Lubbock, TX 79430-6592, USA. ${ }^{2}$ Center of Excellence for Translational Neuroscience and Therapeutics, Texas Tech University Health Sciences Center, Lubbock, TX, USA. ${ }^{3}$ Garrison Institute on Aging, Texas Tech University Health Sciences Center, Lubbock, TX, USA.

Received: 21 July 2020 Accepted: 9 September 2020 Published online: 18 September 2020

\section{References}

1. Neugebauer V, Li W, Bird GC, Han JS. The amygdala and persistent pain. Neuroscientist. 2004;10:221-34.

2. Neugebauer V. Amygdala physiology in pain. Handbook of Behavioral Neurosciences. 2020;26:101-13.

3. Kato F, Sugimura YK, Takahashi Y. Pain-associated neural plasticity in the Parabrachial to central amygdala circuit : pain changes the brain, and the brain changes the pain. Adv Exp Med Biol. 2018;1099:157-66.

4. Wilson TD, Valdivia S, Khan A, Ahn HS, Adke AP, Martinez GS, Sugimura YK, Carrasquillo Y. Dual and opposing functions of the central amygdala in the modulation of pain. Cell Rep. 2019;29:332-46.
5. Veinante $P$, Yalcin I, Barrot $M$. The amygdala between sensation and affect: a role in pain. J Mol Psychiatry. 2013;1:9.

6. Thompson JM, Neugebauer V. Amygdala plasticity and pain. Pain Res Manag. 2017:2017:8296501.

7. Han JS, Neugebauer V. mGluR1 and mGluR5 antagonists in the amygdala inhibit different components of audible and ultrasonic vocalizations in a model of arthritic pain. Pain. 2005;113:211-22.

8. Ji G, Li Z, Neugebauer V. Reactive oxygen species mediate visceral painrelated amygdala plasticity and behaviors. Pain. 2015;156:825-36.

9. Minami M. Neuronal mechanisms for pain-induced aversion behavioral studies using a conditioned place aversion test. Int Rev Neurobiol. 2009;85: 135-44.

10. Bourbia N, Ansah OB, Pertovaara A. Corticotropin-releasing factor in the rat amygdala differentially influences sensory-discriminative and emotional-like pain response in peripheral neuropathy. J Pain. 2010;11: 1461-71.

11. Ansah OB, Bourbia N, Goncalves L, Almeida A, Pertovaara A. Influence of amygdaloid glutamatergic receptors on sensory and emotional pain-related behavior in the neuropathic rat. Behav Brain Res. 2010;209:174-8.

12. Sagalajev B, Bourbia N, Beloushko E, Wei H, Pertovaara A. Bidirectional amygdaloid control of neuropathic hypersensitivity mediated by descending serotonergic pathways acting on spinal 5-HT3 and 5-HT1A receptors. Behav Brain Res. 2015:282:14-24.

13. Ji G, Fu Y, Ruppert KA, Neugebauer V. Pain-related anxiety-like behavior requires CRF1 receptors in the amygdala. Mol Pain. 2007;3:13-7.

14. Ji G, Zhang W, Mahimainathan L, Narasimhan M, Kiritoshi T, Fan X, Wang J, Green TA, Neugebauer V. 5-HT2C receptor knockdown in the amygdala inhibits neuropathic-pain-related plasticity and behaviors. J Neurosci. 2017; 37:1378-93.

15. Thompson JM, Yakhnitsa V, Ji G, Neugebauer V. Small conductance calcium activated potassium (SK) channel dependent and independent effects of riluzole on neuropathic pain-related amygdala activity and behaviors in rats. Neuropharmacology. 2018;138:219-31.

16. Navratilova E, Ji G, Phelps C, Qu C, Hein M, Yakhnitsa V, Neugebauer V Porreca F. Kappa opioid signaling in the central nucleus of the amygdala promotes disinhibition and aversiveness of chronic neuropathic pain. Pain. 2019;160:824-32.

17. Carrasquillo Y, Gereau RW. Activation of the extracellular signal-regulated kinase in the amygdala modulates pain perception. J Neurosci. 2007;27: 1543-51.

18. Rea K, Olango WM, Harhen B, Kerr DM, Galligan R, Fitzgerald S, Moore M, Roche M, Finn DP. Evidence for a role of GABAergic and glutamatergic signalling in the basolateral amygdala in endocannabinoid-mediated fearconditioned analgesia in rats. Pain. 2013;154:576-85.

19. Rea K, Roche M, Finn DP. Modulation of conditioned fear, fear-conditioned analgesia, and brain regional c-Fos expression following administration of muscimol into the rat basolateral amygdala. J Pain. 2011:12:712-21.

20. Butler RK, Ehling S, Barbar M, Thomas J, Hughes MA, Smith CE, Pogorelov VM, Aryal DK, Wetsel WC, Lascelles BDX. Distinct neuronal populations in the basolateral and central amygdala are activated with acute pain, conditioned fear, and fear-conditioned analgesia. Neurosci Lett. 2017;661: $11-7$

21. McGaraughty S, Heinricher MM. Microinjection of morphine into various amygdaloid nuclei differentially affects nociceptive responsiveness and RVM neuronal activity. Pain. 2002;96:153-62.

22. Ortiz JP, Heinricher MM, Selden NR. Noradrenergic agonist administration into the central nucleus of the amygdala increases the tail-flick latency in lightly anesthetized rats. Neuroscience. 2007;148:737-43.

23. Min MY, Yang HW, Yen CT, Chen CC, Chen CC, Cheng SJ. ERK, synaptic plasticity and acid-induced muscle pain. Commun Integr Biol. 2011;4:394-6.

24. Manning $\mathrm{BH}$. A lateralized deficit in morphine antinociception after unilateral inactivation of the central amygdala. J Neurosci. 1998;18:9453-70.

25. Manning BH, Martin WJ, Meng ID. The rodent amygdala contributes to the production of cannabinoid-induced antinociception. Neuroscience. 2003; 120:1157-70.

26. Kolber BJ, Montana MC, Carrasquillo Y, Xu J, Heinemann SF, Muglia L, Gereau RW. Activation of metabotropic glutamate receptor 5 in the amygdala modulates pain-like behavior. J Neurosci. 2010:30:8203-13.

27. Gregoire S, Neugebauer V. 5-HT2CR blockade in the amygdala conveys analgesic efficacy to SSRIs in a rat model of arthritis pain. Mol Pain. 2013;9: 41. 
28. Corder G, Ahanonu B, Grewe BF, Wang D, Schnitzer MJ, Scherrer G. An amygdalar neural ensemble that encodes the unpleasantness of pain. Science. 2019;363:276-81.

29. Medina G, Ji G, Gregoire S, Neugebauer V. Nasal application of neuropeptide $S$ inhibits arthritis pain-related behaviors through an action in the amygdala. Mol Pain. 2014;10:32.

30. Thompson JM, Ji G, Neugebauer V. Small-conductance calcium-activated potassium (SK) channels in the amygdala mediate pain-inhibiting effects of clinically available riluzole in a rat model of arthritis pain. Mol Pain. 2015;11: 51.

31. Cragg B, Ji G, Neugebauer V. Differential contributions of vasopressin V1A and oxytocin receptors in the amygdala to pain-related behaviors in rats. Mol Pain. 2016;12:1744806916676491.

32. Kim H, Thompson J, Ji G, Ganapathy V, Neugebauer V. Monomethyl fumarate inhibits pain behaviors and amygdala activity in a rat arthritis model. Pain. 2017;158:2376-85.

33. Latremoliere A, Woolf CJ. Central sensitization: a generator of pain hypersensitivity by central neural plasticity. J Pain. 2009;10:895-926.

34. Sandkuhler J. Translating synaptic plasticity into sensation. Brain. 2015;138: 2463-4.

35. Heinricher MM, Tavares I, Leith JL, Lumb BM. Descending control of nociception: specificity, recruitment and plasticity. Brain Res Rev. 2009;60: 214-25.

36. Li JN, Sheets PL. The central amygdala to periaqueductal gray pathway comprises intrinsically distinct neurons differentially affected in a model of inflammatory pain. J Physiol. 2018;596:6289-305.

37. Dickenson AH, Navratilova E, Patel R, Porreca F, Bannister K. Supraspinal opioid circuits differentially modulate spinal neuronal responses in neuropathic rats. Anesthesiology. 2020;132:881-94.

38. Bruchas MR, Land BB, Chavkin C. The dynorphin/kappa opioid system as a modulator of stress-induced and pro-addictive behaviors. Brain Res. 2010; 1314:44-55.

39. Pomrenze MB, Millan EZ, Hopf FW, Keiflin R, Maiya R, Blasio A, Dadgar J, Kharazia V, De GG, Crawford E, et al. A transgenic rat for investigating the anatomy and function of corticotrophin releasing factor circuits. Front Neurosci. 2015:9:487.

40. De Guglielmo G, Kallupi M, Pomrenze MB, Crawford E, Simpson S, Schweitzer P, Koob GF, Messing RO, George O. Inactivation of a CRFdependent amygdalofugal pathway reverses addiction-like behaviors in alcohol-dependent rats. Nat Commun. 2019;10:1238.

41. Pomrenze MB, Giovanetti SM, Maiya R, Gordon AG, Kreeger LJ, Messing $\mathrm{RO}$. Dissecting the roles of GABA and neuropeptides from rat central amygdala CRF neurons in anxiety and fear learning. Cell Rep. 2019;29: $13-21$.

42. Ji G, Neugebauer $\mathrm{V}$. Contribution of Corticotropin-releasing factor receptor 1 (CRF1) to serotonin receptor $5-\mathrm{HT} 2 \mathrm{CR}$ function in amygdala neurons in a neuropathic pain model. Int J Mol Sci. 2019;20(18):4380

43. Ji G, Yakhnitsa V, Kiritoshi T, Presto P, Neugebauer V. Fear extinction learning ability predicts neuropathic pain behaviors and amygdala activity in male rats. Mol Pain. 2018;14:1744806918804441.

44. Yuan SB, Ji G, Li B, Andersson T, Neugebauer V, Tang SJ. A Wnt5a signaling pathway in the pathogenesis of HIV-1 gp120-induced pain. Pain. 2015;156: 1311-9.

45. Mazzitelli M, Neugebauer V. Amygdala group II mGluRs mediate the inhibitory effects of systemic group II mGluR activation on behavior and spinal neurons in a rat model of arthritis pain. Neuropharmacology. 2019; 158:107706

46. Fu $Y$, Neugebauer $V$. Differential mechanisms of CRF1 and CRF2 receptor functions in the amygdala in pain-related synaptic facilitation and behavior. J Neurosci. 2008:28:3861-76.

47. Fu Y, Han J, Ishola T, Scerbo M, Adwanikar H, Ramsey C, Neugebauer V. PKA and ERK, but not PKC, in the amygdala contribute to pain-related synaptic plasticity and behavior. Mol Pain. 2008;4:26-46.

48. Kiritoshi T, Ji G, Neugebauer V. Rescue of Impaired mGluR5-driven Endocannabinoid signaling restores prefrontal cortical output to inhibit pain in arthritic rats. J Neurosci. 2016;36:837-50.

49. Ji G, Neugebauer $V$. Hemispheric lateralization of pain processing by amygdala neurons. J Neurophysiol. 2009;1102:2253-64.

50. Ji G, Neugebauer V. CB1 augments mGluR5 function in medial prefrontal cortical neurons to inhibit amygdala hyperactivity in an arthritis pain model. Eur J Neurosci. 2014;39:455-66.
51. Land BB, Bruchas MR, Lemos JC, Xu M, Melief EJ, Chavkin C. The dysphoric component of stress is encoded by activation of the dynorphin kappaopioid system. J Neurosci. 2008;28:407-14.

52. Crowley NA, Bloodgood DW, Hardaway JA, Kendra AM, McCall JG, Al-Hasani R, McCall NM, Yu W, Schools ZL, Krashes MJ, et al. Dynorphin controls the gain of an Amygdalar anxiety circuit. Cell Rep. 2016;14:2774-83.

53. Lalanne L, Ayranci G, Kieffer BL, Lutz PE. The kappa opioid receptor: from addiction to depression, and back. Front Psychiatry. 2014;5:170.

54. Smith JS, Schindler AG, Martinelli E, Gustin RM, Bruchas MR, Chavkin C. Stress-induced activation of the dynorphin/kappa-opioid receptor system in the amygdala potentiates nicotine conditioned place preference. J Neurosci. 2012:32:1488-95.

55. Xie JY, De FM, Kopruszinski CM, Eyde N, LaVigne J, Remeniuk B, Hernandez P, Yue X, Goshima N, Ossipov M, et al. Kappa opioid receptor antagonists: a possible new class of therapeutics for migraine prevention. Cephalalgia. 2017;37:780-94.

56. Nation KM, De FM, Hernandez PI, Dodick DW, Neugebauer V, Navratilova E, Porreca F. Lateralized kappa opioid receptor signaling from the amygdala central nucleus promotes stress-induced functional pain. Pain. 2018;159: 919-28.

57. Phelps CE, Navratilova E, Dickenson AH, Porreca F, Bannister K. Kappa opioid signaling in the right central amygdala causes hind paw specific loss of diffuse noxious inhibitory controls in experimental neuropathic pain. Pain. 2019;160:1614-21.

58. Cahill CM, Taylor AM, Cook C, Ong E, Moron JA, Evans CJ. Does the kappa opioid receptor system contribute to pain aversion? Front Pharmacol. 2014; 5:253.

59. Zhou L, Lovell KM, Frankowski KJ, Slauson SR, Phillips AM, Streicher JM, Stahl E, Schmid CL, Hodder P, Madoux F, et al. Development of functionally selective, small molecule agonists at kappa opioid receptors. J Biol Chem. 2013;288:36703-16.

60. Gilpin NW, Roberto M, Koob GF, Schweitzer P. Kappa opioid receptor activation decreases inhibitory transmission and antagonizes alcohol effects in rat central amygdala. Neuropharmacology. 2014;77:294-302.

61. Kang-Park M, Kieffer BL, Roberts AJ, Siggins GR, Moore SD. kappa-opioid receptors in the central amygdala regulate ethanol actions at presynaptic GABAergic sites. J Pharmacol Exp Ther. 2013;346:130-7.

62. Chieng BC, Christie MJ, Osborne PB. Characterization of neurons in the rat central nucleus of the amygdala: cellular physiology, morphology, and opioid sensitivity. J Comp Neurol. 2006;497:910-27.

63. Zhu W, Pan ZZ. Synaptic properties and postsynaptic opioid effects in rat central amygdala neurons. Neuroscience. 2004;127:871-9.

64. Carrasquillo Y, Gereau RW. Hemispheric lateralization of a molecular signal for pain modulation in the amygdala. Mol Pain. 2008;4:24.

65. Sadler KE, McQuaid NA, Cox AC, Behun MN, Trouten AM, Kolber BJ. Divergent functions of the left and right central amygdala in visceral nociception. Pain. 2017:158:747-59.

66. Navratilova E, Nation K, Remeniuk B, Neugebauer V, Bannister K, Dickenson $\mathrm{AH}$, Porreca F. Selective modulation of tonic aversive qualities of neuropathic pain by morphine in the central nucleus of the amygdala requires endogenous opioid signaling in the anterior cingulate cortex. Pain. 2020;161:609-18.

67. Marcilhac A, Siaud P. Identification of projections from the central nucleus of the amygdala to the paraventricular nucleus of the hypothalamus which are immunoreactive for corticotrophin-releasing hormone in the rat. Exp Physiol. 1997;82:273-81.

68. Fendt M, Koch M, Schnitzler HU. Corticotropin-releasing factor in the caudal pontine reticular nucleus mediates the expression of fear-potentiated startle in the rat. Eur J Neurosci. 1997;9:299-305.

69. McCall JG, Al-Hasani R, Siuda ER, Hong DY, Norris AJ, Ford CP, Bruchas MR $\mathrm{CRH}$ engagement of the locus Coeruleus noradrenergic system mediates stress-induced anxiety. Neuron. 2015;87:605-20.

70. Kang-Park M, Kieffer BL, Roberts AJ, Siggins GR, Moore SD. Interaction of CRF and kappa opioid systems on GABAergic neurotransmission in the mouse central amygdala. J Pharmacol Exp Ther. 2015;355:206-11.

71. Penzo MA, Robert V, Li B. Fear conditioning potentiates synaptic transmission onto long-range projection neurons in the lateral subdivision of central amygdala. J Neurosci. 2014;34:2432-7.

72. Bowers LK, Swisher CB, Behbehani MM. Membrane and synaptic effects of corticotropin-releasing factor on periaqueductal gray neurons of the rat. Brain Res. 2003;981:52-7. 
73. Zhuo M. Descending facilitation. Mol Pain. 2017;13:1744806917699212.

74. Toyoda H, Li XY, Wu LJ, Zhao MG, Descalzi G, Chen T, Koga K, Zhuo M. Interplay of amygdala and cingulate plasticity in emotional fear. Neural Plast. 2011:2011:813749.

75. Gozzi A, Jain A, Giovannelli A, Bertollini C, Crestan V, Schwarz AJ, Tsetsenis T, Ragozzino D, Gross CT, Bifone A. A neural switch for active and passive fear. Neuron. 2010;67:656-66.

76. Sharma KK, Kelly EA, Pfeifer CW, Fudge JL. Translating fear circuitry: amygdala projections to Subgenual and Perigenual anterior cingulate in the macaque. Cereb Cortex. 2020;30:550-62.

77. Gebhart GF. Descending modulation of pain. Neurosci Biobehav Rev. 2004; 27:729-37.

78. Neugebauer V. Serotonin - pain modulation. Handbook of Behavioral Neurosciences. 2020;31:309-20.

79. Wiegert JS, Mahn M, Prigge M, Printz Y, Yizhar O. Silencing neurons: tools, applications, and experimental constraints. Neuron. 2017;95:504-29.

80. Madisen L, Mao T, Koch H, Zhuo JM, Berenyi A, Fujisawa S, Hsu YW, Garcia AJ 3rd, Gu X, Zanella S, et al. A toolbox of Cre-dependent optogenetic transgenic mice for light-induced activation and silencing. Nat Neurosci. 2012;15:793-802.

\section{Publisher's Note}

Springer Nature remains neutral with regard to jurisdictional claims in published maps and institutional affiliations.

- fast, convenient online submission

- thorough peer review by experienced researchers in your field

- rapid publication on acceptance

- support for research data, including large and complex data types

- gold Open Access which fosters wider collaboration and increased citations

- maximum visibility for your research: over $100 \mathrm{M}$ website views per year

At BMC, research is always in progress.

Learn more biomedcentral.com/submissions 